\title{
Analysis on the Effect of Slideway Friction to the Slider-Type Hydraulic Powered Support
}

\author{
Yang YANG, Qingliang ZENG, Lirong WAN, Peng LIU
}

\begin{abstract}
This paper presents a design concept of the slider-type hydraulic powered support. The equivalent mechanical model is established when the hydraulic powered support supporting the stable roof pressure and deriving the numerical calculation formula of the supporting efficiency is based on the slideway frictional coefficient. Meanwhile, theoretical solutions of supporting efficiency at different working heights are obtained. On this basis, the rigid-flexible coupling simulation model of the support was established by using Hypermesh and Adams and the dynamic simulation was carried out under the condition that the roof is bearing the stable pressure, and finally, obtaining the force response curves and the simulation solutions of the supporting efficiency. The final analysis shows the following: The slider-type powered support is suitable for working at high position; with the increase of the friction coefficient between the slider and the slideway, the supporting efficiency increases gradually, the working safety and reliability are enhanced, furthermore, its shock resistance and stability are enhanced.
\end{abstract}

Keywords: mechanical model; rigid-flexible coupling simulation model; slideway friction; slider-type powered support

\section{INTRODUCTION}

Hydraulic powered support $[1 \div 10]$ is important equipment in comprehensive mechanized coal mining. It plays a supporting role in coal working face of underground, through its interaction with the surrounding rock, it can control the roof strata in the mining areas and provide safe operating space for working face. Meanwhile, the mechanization of coal mining can be achieved by its use with the shearer and scraper conveyor. Since the British successfully developed powered support in 1854, the Soviet Union developed KTY shield type powered support in 1957 and used it in the Kuzbass coalfield's Sinsk mine. The G550-22/60 shield type powered support was developed by the West German Herschel Company in 1980, the maximum height of which is $6 \mathrm{~m}$. After several reforms and rapid development of the high yield and high efficiency combined mining technology in major coal producing countries (especially in the United States, Australia, Germany, the United Kingdom, South Africa, etc.) from the late 1980s to the present [11], coal mining has formed a mature technology system integrating coal mining, coal loading, coal transportation, support, coal treatment and other processes [12]. In this process, the powered support technology has also achieved technical breakthroughs and developed and improved gradually. Now powered supports which are put into application also have various types and specifications: In terms of types, supports can be categorized into supporting-type powered support, shieldtype powered support, and standing shield powered support. In terms of weight, supports can be categorized into light powered support, medium powered support and heavy powered support. In terms of supporting height, supports can be categorized into thin seam powered support, medium seam powered support, and thick seam powered support. Medium seam powered support can be further subdivided into overall height mining powered support, slicing mining powered support and top coal caving powered support, while in terms of using purpose, supports can be categorized into termination point powered support and intermediate powered support. So far, hydraulic powered support has been developed to a rounded system.

Along with the development and perfection of the types and specifications of powered supports, various in- depth researches on powered support have been spread by domestic and foreign scholars $[13 \div 27]$. In order to research the interaction between powered support and surrounding rock, Verma and Deb developed the finite element models including powered support, surrounding rock and broken rock [28]. Zhao et al. applied finite element analysis and fatigue test method to study the support and provided the theoretical reference for the fatigue design of the welding structure of powered support [29]. González-Nicieza et al. presented a study of the support system in an anthracite working situated in Feixolin. In order to determine the maximum pressure, a model of the working behaviour was built by FLAC [30]. Based on hybrid structural and unstructured finite element mesh, Wang et al. carried out the force loading analysis to the double-telescopic prop of the powered support and used buckling analysis methods to analyze the props stability. The results of the analysis provided a theoretical reference for the new proposed hydro-cylinder technology standard [31]. Oblak, Harl and Butinar proposed a program based on mathematical programming methods to optimize the powered support [32]. The above studies provide a theoretical reference and analytical method for the optimization design, reliability design and using safety of powered support. But these studies are carried out based on the traditional types of powered support, the response of the hydraulic oil in the prop and balanced jack are obtained from the simulation results of hydraulic system of the support through input given parameters to hydraulic system analysis software Amesim. However, the influence of the friction between the different components on the performance of powered support is not considered and they cannot simulate the flexible response of the hydraulic oil in the prop and balanced jack in the process of powered support working without the hydraulic system simulation software. Therefore, it is impossible to obtain the exact response of the support when bearing the roof pressure without fluid flow analysis through the traditional analysis method.

China is the world's major coal-producing country. The quantity of the coal mines is more than the total sum of all other countries around the world. It is not only rich in resources but also widely distributed in coal resources, which lead to the diversity and complexity of coal seams. To solve this situation, different coal mining methods and 
different types of support are adopted in different coal mines. However, with the changing of the domestic and international economic situation, the inherent defect of the existing coal mining equipment is gradually revealed. According to the proved reserves of coal, China is rich in thin and medium thickness coal seams, and only the recoverable reserves of coal seams below $1.3 \mathrm{~m}$ account for more than $20 \%$ of the total recoverable coal reserves in China. For this kind of coal seam, the domestic usually adopt the mining method of mechanized mining by coal plough or drum shearer at present, and the support used is shield-type powered support, especially the two-column shield-type powered support. However, the current domestic thin coal seam production in China just accounts for $10.4 \%$ of the total national output, the shelve of thin coal seam causes serious waste of coal resources [33], and the consuming energy and investment capital in the mining process of medium thick coal seam is also larger. This puts forward new requirements on coal mining machinery reducing energy consumption and increasing mining rates. Thus, it has great significance for the development of the Chinese coal industry to improve the existing two-column shield-type powered support and make it better adapt to the mining conditions of thin and medium thickness coal seam. On the basis of many years of research on traditional fully mechanized mining matching equipment, the authors designed a new slider-type powered support [34] according to the advantages and disadvantages of the traditional twocolumn shield-type powered support. The new powered support not only can achieve larger magnification ratio but also can improve the supporting efficiency and reduce the energy consumption. Then, we analyzed and researched the slider-type powered support. The mathematical model of supporting efficiency of the powered support based on the slideway friction was established, and the simulation of the slider-type powered support is innovatively combined with Hypermesh and Adams. By the simulation, we got the accurate response of the support under triangle roof pressure and obtained the influence law of the slideway friction to support's working performance. Through the equivalence of the slider-type powered support's hydrocylinder to the liquid spring with certain stiffness, the problem that the compressibility of hydraulic oil cannot be simulated in the dynamic simulation analysis of powered support without hydraulic system simulation software is solved.

The contributions of the paper include:

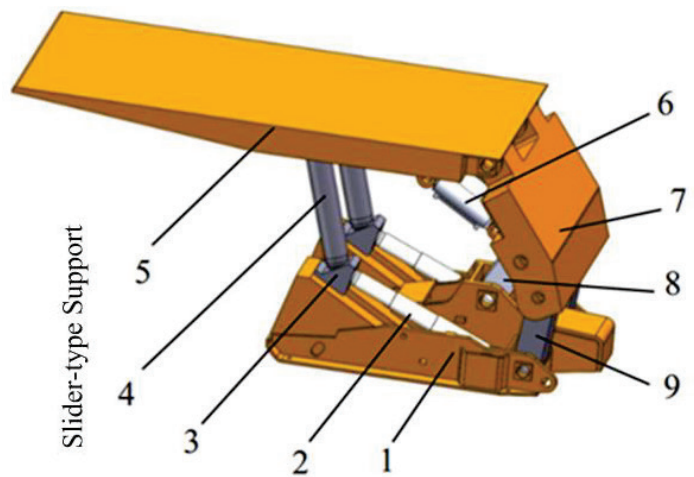

Figure 1 Simplified structural model of the powered support

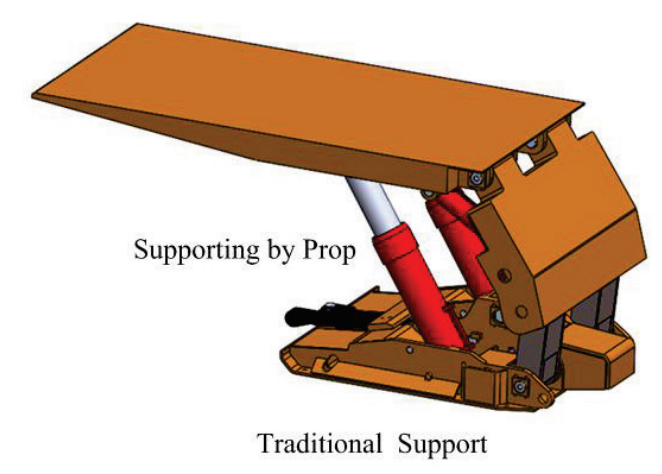

- Establish the mathematical model of the roof supporting efficiency of the slider-type powered support based on the friction between the slider and slideway in the static equilibrium state.

- Present an equivalent method for hydro-cylinder of slider-type powered support and introduce the method of dynamic simulation analysis on powered support based on Hypermesh and Adams.

- Obtain the variation law of the roof supporting efficiency of powered support with the changing of the frictional coefficient between the slider and slideway.

The remainder of the paper is organized as follows: Section 2 introduces the structure of the slider-type powered support and establishes the roof supporting efficiency mathematical model based on the friction between the slider and slideway. Section 3 introduces the dynamic simulation analysis process of the rigid-flexible coupling model of the slider-type powered support and discusses the equivalent treatment method of the hydrocylinder. Section 4 compares the roof supporting efficiency of the theoretical values and simulation results, thus obtains the variation law of the roof supporting efficiency of powered support with the changing of the frictional coefficient between the slider and slideway. Section 5 shows some related work and our conclusions.

\section{MATHEMATICAL MODEL OF SUPPORTING EFFICIENCY OF THE SLIDER-TYPE POWERED SUPPORT}

\subsection{Structural Model of the Slider-Type Powered Support}

The slider-type powered support is the new two column shield-type powered support which improves the traditional height adjusting method (prop) based on the traditional two column shield powered support. As shown in the simplified structural model of the powered support Fig. 1, the slider-type powered support is mainly composed of 9 parts, such as the base-1, adjustment jack-2, slider-3, vertical bar-4, top beam-5, balanced jack-6, shield beam-7, front linkage-8, and rear linkage-9, which cancels height adjusting device of the traditional powered support-prop, it brings about the height adjusting of the new slider-type powered support through the jointly load-transferring system composed by the inclined ramp set on the front end of the base 1, adjustment jack 2, slider 3 and vertical bar 4 . 
When the slider-type powered support is arranged in the coal mining face under the mine, the mobile column of the adjustment jack is stretching and shrinking regularly in the oil pressure of the pumping station which makes slider slide up and down along the slideway. For example, when we need to lift the support, the adjustment jack will push the slider slide up along the slideway, the included angle between the vertical bar and top beam will change accordingly and the vertical bar will swing a certain angle around the upper column nest set on the top beam. At the same time, the slider horizontal move to the coal wall side and the stability of support is improved for the increasing of horizontal distance between the slider and front linkage and rear linkage.

\subsection{Mathematical Model of the Supporting Efficiency Based on the Slideway Friction}

The supporting efficiency of the traditional two column shield-type powered support as an intuitive parameter to evaluate the effective degree of the working resistance of the prop is transformed into the working resistance of the support and the supporting efficiency is $\eta^{\prime}=F / p_{t}\left(F\right.$ : Working resistance of the powered support, $p_{t}$ : Working resistance of the support's prop). For the reason that the slider-type powered support cancels the traditional supporting mechanism-prop and adds the power mechanism adjustment jack, the definition of the slidertype powered support's roof supporting efficiency $\eta$ is defined as the ratio of the roof pressure (i.e. Working resistance of the powered support) and working pressure of the adjustment jack (i.e. Working resistance of the support's prop), i.e., $\eta=F_{\text {roof }} / F_{\text {adjusting. }}$.

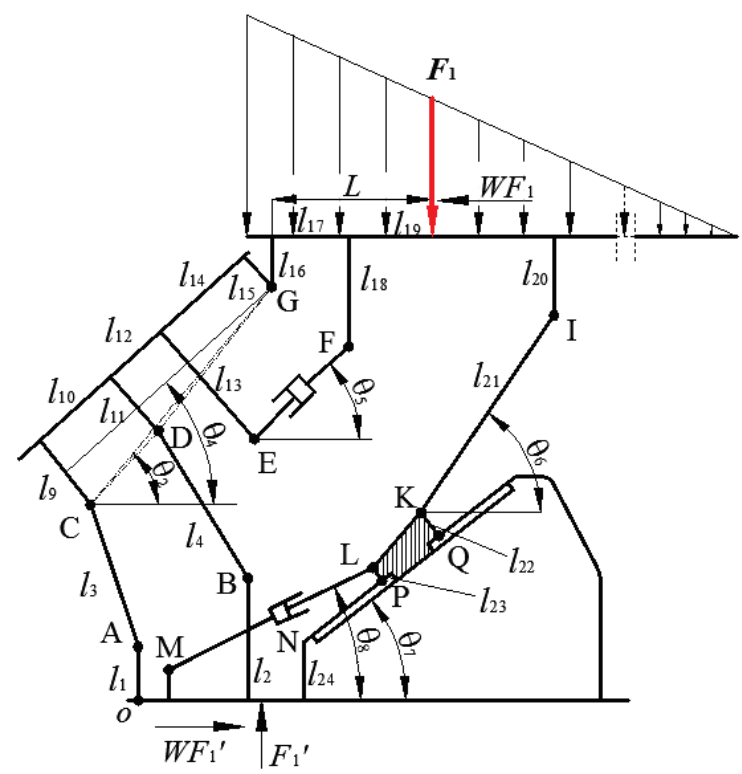

Figure 2 Bearing structure diagram of the slider-type support

The supporting efficiency of the powered support is decided to its type, structure and working height et al. To explore its changing forms and influencing factors, the two-dimensional equivalent model of the slider-type powered support is established and the mathematical supporting efficiency model of the support under a certain form roof pressure is built. Taking the roof load as the triangular distribution and neglecting the self-gravity of each component of support and compressibility of hydraulic oil, we establish the mechanical model of the slider-type powered support when working underground shown in Fig. 2. $F_{1}$ is the equivalent concentrated load applied to the top beam by the roof, $F_{1}{ }^{\prime}$ is the supporting force that the floor supports the base of the support. $W F_{1}$ is the friction between the top beam and the roof, $W F_{1}{ }^{\prime}$ is the friction between the base and the floor. When the support is working in a certain height $H$, the slider has a downward tendency along the slideway on account of the roof pressure, the frictional resistance $F_{f}$ upward along the slideway between the undersurface of the slider and the slideway will be produced. According to the above, the force analysis diagram of the support's main components such as the top beam, shield beam and slide is established, as shown in Fig. 3.

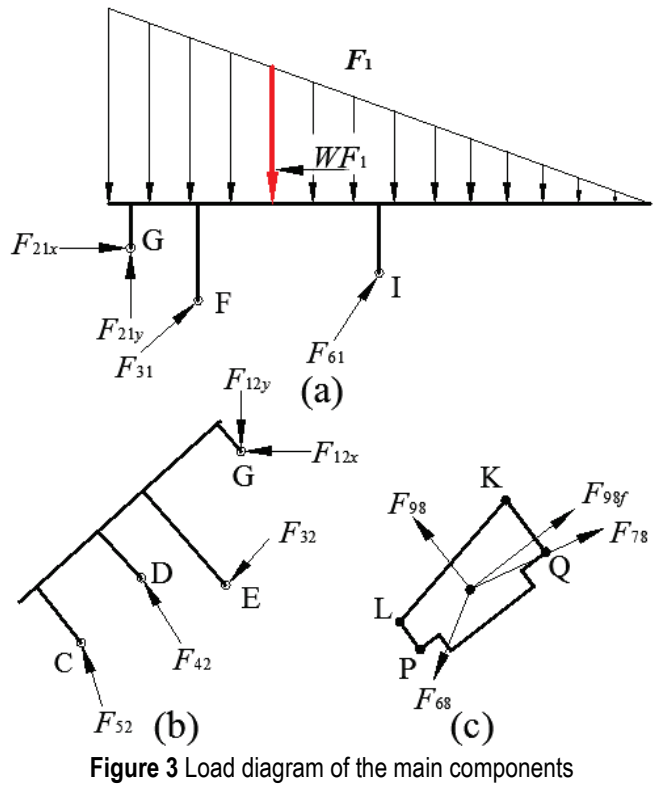

Regarding the top beam, shield beam and slider as detached bodies respectively, as shown in Fig. 3(a), Fig. 3(b) and Fig. 3(c) there are the following constraints from Fig. 2 and Fig. 3: $F_{1}{ }^{\prime}=F_{1}, F_{21 x}=F_{12 x}, F_{21 y}=F_{12 y}, F_{31}=F_{32}$, $F_{61}=F_{68}$. From the relationship between the position of components and the loading state of the support bearing model in Fig. 2 and Fig. 3, the force equilibrium equation of the slider-type support [35] under height $\mathrm{H}$ is established:

$$
\left\{\begin{array}{l}
F_{21 x}+F_{31} \cdot \cos \theta_{5}+F_{61} \cdot \cos \theta_{6}=W \cdot F_{1} \\
F_{21 y}+F_{31} \cdot \sin \theta_{5}+F_{61} \cdot \sin \theta_{6}=F_{1} \\
F_{12 x}+F_{32} \cdot \cos \theta_{5}+F_{42} \cdot \cos \theta_{3}+F_{52} \cdot \cos \theta_{1}=0 \\
F_{12 y}+F_{32} \cdot \sin \theta_{5}=F_{42} \cdot \sin \theta_{3}+F_{52} \cdot \sin \theta_{1} \\
F_{68} \cdot \cos \theta_{6}+F_{98} \cdot \sin \theta_{7}=F_{98 f} \cdot \cos \theta_{7}+F_{78} \cdot \cos \theta_{8} \\
F_{68} \cdot \sin \theta_{6}=F_{98} \cdot \cos \theta_{7}+F_{98 f} \cdot \sin \theta_{7}+F_{78} \cdot \sin \theta_{8} \\
F_{31} \cdot A+F_{61} \cdot B+W \cdot F_{1} \cdot l_{16}=F_{1} \cdot L \\
F_{32} \cdot C+F_{42} \cdot D+F_{52} \cdot E=0
\end{array}\right.
$$

where: $F_{i j}$ is the force of component $i$ on component $j, F_{i j x}$ and $F_{i j y}$ are the decomposition of $F_{i j}$ along $x$ and $y$ axis 
respectively, $W$ is the frictional coefficient between the top beam and the roof (the value of $\mathrm{W}$ is taken as 0.3 in here), $L$ is the distance from the action spot of concentrated load $F_{1}$ to the hinged joint between the shield beam and the top beam, and $F_{98 f}=f \cdot F_{98}$ with the condition that the frictional coefficient between steel and steel is $f$.

Solution is obtained:

$F_{31}=\left(\frac{P}{A}-\frac{V \cdot Q-M \cdot U}{N \cdot Q-M \cdot T} \cdot \frac{B}{A}\right) \cdot F_{1}$

$F_{61}=\frac{V \cdot Q-M \cdot U}{N \cdot Q-M \cdot T} \cdot F_{1}$

$F_{78}=\frac{\cos \left(\theta_{7}-\theta_{6}\right)+f \cdot \sin \left(\theta_{7}-\theta_{6}\right)}{\cos \left(\theta_{7}-\theta_{8}\right)+f \cdot \sin \left(\theta_{7}-\theta_{8}\right)} \cdot F_{61}$

$\eta=\frac{\cos \left(\theta_{7}-\theta_{8}\right)+f \cdot \sin \left(\theta_{7}-\theta_{8}\right)}{\cos \left(\theta_{7}-\theta_{6}\right)+f \cdot \sin \left(\theta_{7}-\theta_{6}\right)} \cdot \frac{N \cdot Q-M \cdot T}{V \cdot Q-M \cdot U}$

where

$$
\begin{aligned}
& A=\cos \theta_{5} \cdot\left(l_{18}-l_{16}\right)+\sin \theta_{5} \cdot l_{17} \\
& B=\cos \theta_{6} \cdot\left(l_{20}-l_{16}\right)+\sin \theta_{6} \cdot\left(l_{17}+l_{19}\right) \\
& C=\cos \left(\theta_{4}-\theta_{5}\right) \cdot\left(l_{13}-l_{15}\right)+\sin \left(\theta_{4}-\theta_{5}\right) \cdot l_{14}
\end{aligned}
$$

$$
\begin{aligned}
& D=\cos \left(\theta_{3}+\theta_{4}-\frac{\pi}{2}\right) \cdot\left(l_{12}+l_{14}\right)-\sin \left(\theta_{3}+\theta_{4}-\frac{\pi}{2}\right) \cdot\left(l_{11}-l_{15}\right) \\
& E=\cos \left(\theta_{1}+\theta_{4}-\frac{\pi}{2}\right) \cdot\left(l_{10}+l_{12}+l_{14}\right)-\sin \left(\theta_{1}+\theta_{4}-\frac{\pi}{2}\right) \cdot\left(l_{9}-l_{15}\right) \\
& M=E-\frac{D \cdot \cos \theta_{1}}{\cos \theta_{3}}, N=-\frac{B \cdot C}{A}+\frac{D \cdot \cos \theta_{6}}{\cos \theta_{3}} \\
& P=L-W \cdot l_{16}, U=1+W \cdot \tan \theta_{3}, V=-\frac{P \cdot C}{A}+\frac{D \cdot W}{\cos \theta_{3}} \\
& Q=\sin \theta_{1}-\tan \theta_{3} \cdot \cos \theta_{1}, T=\sin \theta_{6}+\tan \theta_{3} \cdot \cos \theta_{6}
\end{aligned}
$$

As the important force transferring mechanism of the slider-type powered support, the force bearing area of the slider is small and the load it bears is large, the wear resistance and strength requirements are higher in the application process. According to the above reasons, the whole slider is produced from Q690 steel. From Fig.2, when the working height is determined, each angle of the slider-type powered support is uniquely determined. Based on the mathematical analysis equation (5) of the roof supporting efficiency we can obtain that the supporting efficiency of the slider-type powered support is closely related to the frictional coefficient $\mathrm{f}$ when working at the same height. When the material of the slider is determined, the value of $\mathrm{f}$ just depends on the material of the slider surface. Therefore, the supporting efficiency depends on the slider's surface material after the position and posture of the slider-type powered support (working height) is determined.

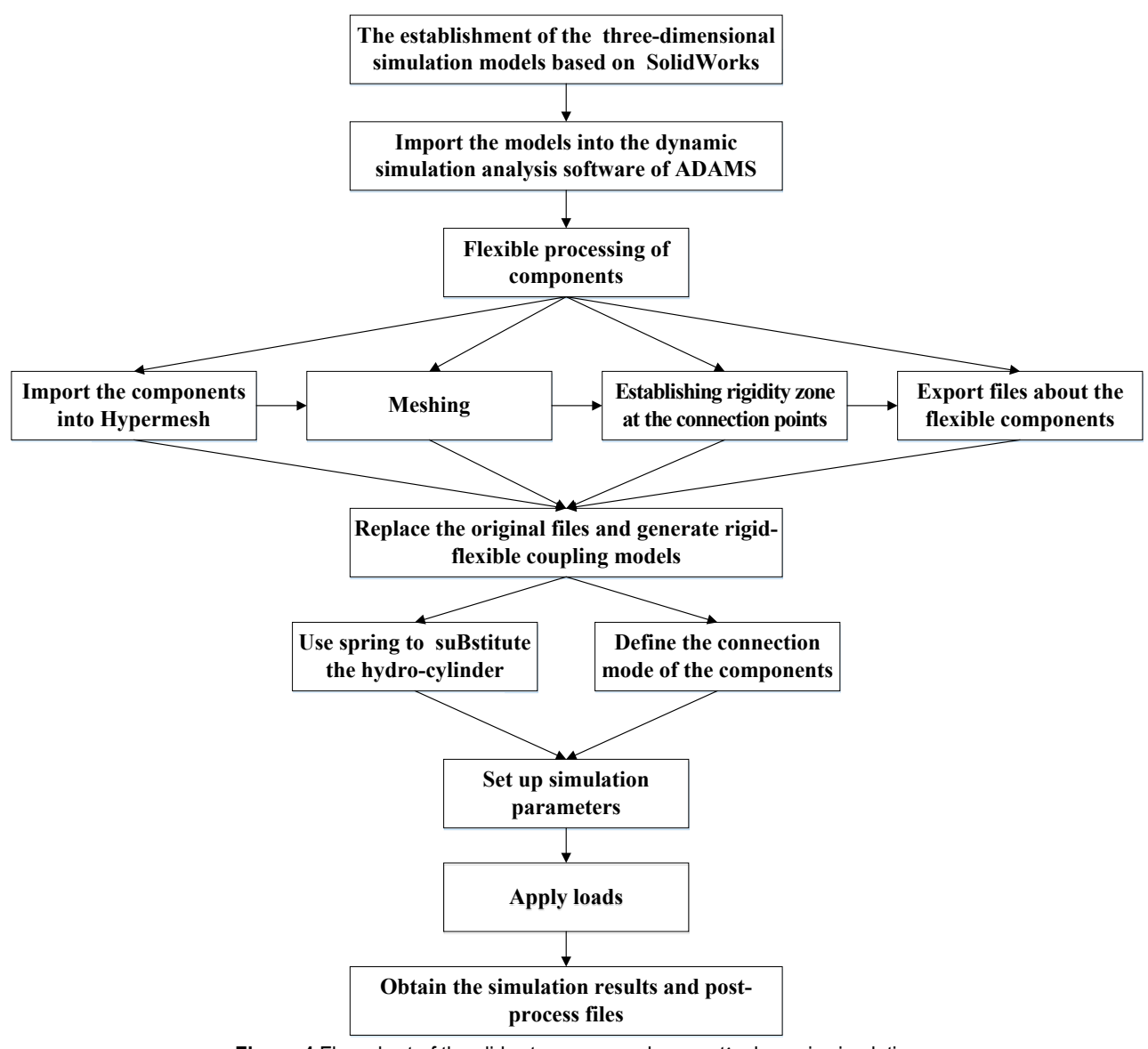

Figure 4 Flow chart of the slider-type powered support's dynamic simulation 


\section{ESTABLISHMENT OF THE RIGID-FLEXIBLE COUPLING DYNAMIC SIMULATION MODEL}

To research the effect of the frictional coefficient between the slideway and slider on the supporting efficiency of slider-type powered support, the multi-body dynamics simulation platform ADAMS combined with professional flexible pre-processing software Hypermesh was used to carry out the loading simulation on the support with different slider surface material. The procedure of dynamic simulation analysis of the rigid-flexible coupling model of the slider-type powered support is shown as Fig. 4.

\subsection{Flexible Processing of Components}

Establish the simulation models at working height 900 $\mathrm{mm}, 1200 \mathrm{~mm}, 1500 \mathrm{~mm}$ respectively. 5 groups of dynamic simulation are carried out on each working height simulation model separately under the condition that the frictional coefficient between the slideway and slider surface is $0.1-0.5$ and the interval is 0.1 . In order to obtain accurate simulation results, after the rigid body simulation model is imported into ADAMS software, we take flexible processing on the rigid body simulation model. As the force-bearing foundation bed, the base is still used as a rigid body. Other main structural components, such as the top beam, shield beam, front linkage and rear linkage are all imported into the professional flexible grid meshing software Hypermesh to carry out the flexible pre-process. The structural components after flexible grid meshing are shown in Fig. 5, as the hinge points of the structural components need to connect with other structural components and transfer the force mutually, the parts close to the hinge points of the components adopt meshing the rigid grid instead of the flexible processing. Rigid connection areas of structural components hinge points are marked with blue circles.

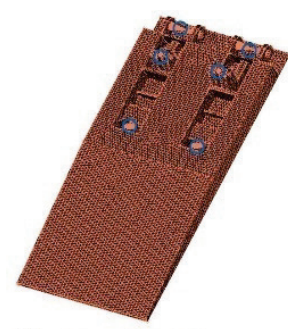

Upper beam

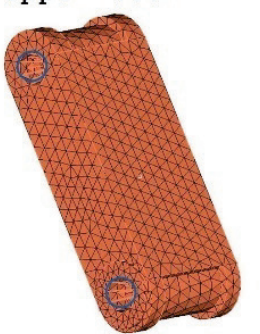

Rear bar

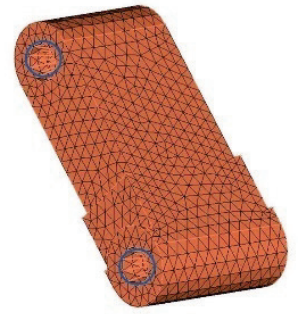

Front bar

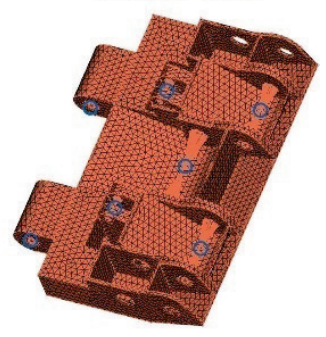

Shield beam

Figure 5 Flexible grid meshing of main structural components

\subsection{Determination of Equivalent Stiffness of Liquid Column}

The emulsifying liquid in the adjustment jack and the balanced jack has the compressibility; the emulsifying liquid will shrink when bearing the roof pressure. At the moment, the working height of the support will be slightly reduced, and the oil pressure in the hydro-cylinder and the balanced jack will be increased accordingly to provide sufficient supporting load to resist the coming roof pressure. The simulation model cancels the rigid hydrocylinder simplified model and a spring damping system is used to replace the adjustment jack and the balanced jack, by determining the reasonable spring stiffness to achieve the simulation of compression positive pressure-boosting characteristics of the hydro-cylinder oil. The determining principle of the liquid spring stiffness (i.e. the equivalent stiffness of hydro-cylinder) is as follows:

$$
\left.\begin{array}{l}
K=\frac{\Delta p \cdot S}{\Delta l} \\
E_{r}=\frac{\Delta p \cdot V_{0}}{\Delta V}
\end{array}\right\}
$$

where: $K-$ The equivalent stiffness coefficient of the liquid spring, $\mathrm{N} / \mathrm{m}$, the tandem stiffness of the double telescopic hydro-cylinder $K=K_{1} \cdot K_{2} /\left(K_{1}+K_{2}\right) ; S$ - Pressure bearing area of the liquid; $E_{r}-$ Volume elastic modulus of the liquid medium, the value of the emulsifying liquid is $1.95 \times 10^{3} \mathrm{MPa} ; l-$ Length of effective fluid column in hydo-cylinder, $\mathrm{mm} ; \Delta l-$ The compressed length of the hydraulic oil, $\mathrm{mm} ; V_{0}$ - Original volume of the hydraulic oil; $\Delta V-$ The changing value of volume of the hydraulic oil after compression; $\Delta p$ - The changing value of pressure of the hydraulic oil after compression

The adjustment jack was in a compressed state regardless of the support at any working height. Thus, the oil pressure bearing area of the adjustment jack is the radial area of the piston of each level hydro-cylinder (The piston diameter $D_{2}$ is equivalent to the matched inner diameter of the hydro-cylinder in the modeling process), the pressure bearing area of the liquid is $S=\pi \cdot D_{2}^{2} / 4$ in here. In the process of supporting efficiency of mathematical model construction, this paper gives a triangular distribution of the roof pressure. According to the Eq. (2), the theoretical value of the force $F_{31}$ of the balanced jack is always negative when the support reaches the static equilibrium in this state, the balanced jack is subjected to the pulling force and the hydraulic oil on the piston rod side of the balanced jack is compressed. The pressure bearing area of the liquid is $S=\pi \cdot\left(D_{2}^{2}-D_{1}{ }^{2}\right) / 4$, and the effective fluid column is the piston rod side fluid column in the oil chamber.

The simplified process of the adjustment jack and the balanced jack in the modeling process is shown in Fig. 6 . According to the Eq. (7), Fig. 6 and Tab. 1, the equivalent stiffness of the hydro-cylinder oil under different working height is obtained, as shown in Tab. 2. 

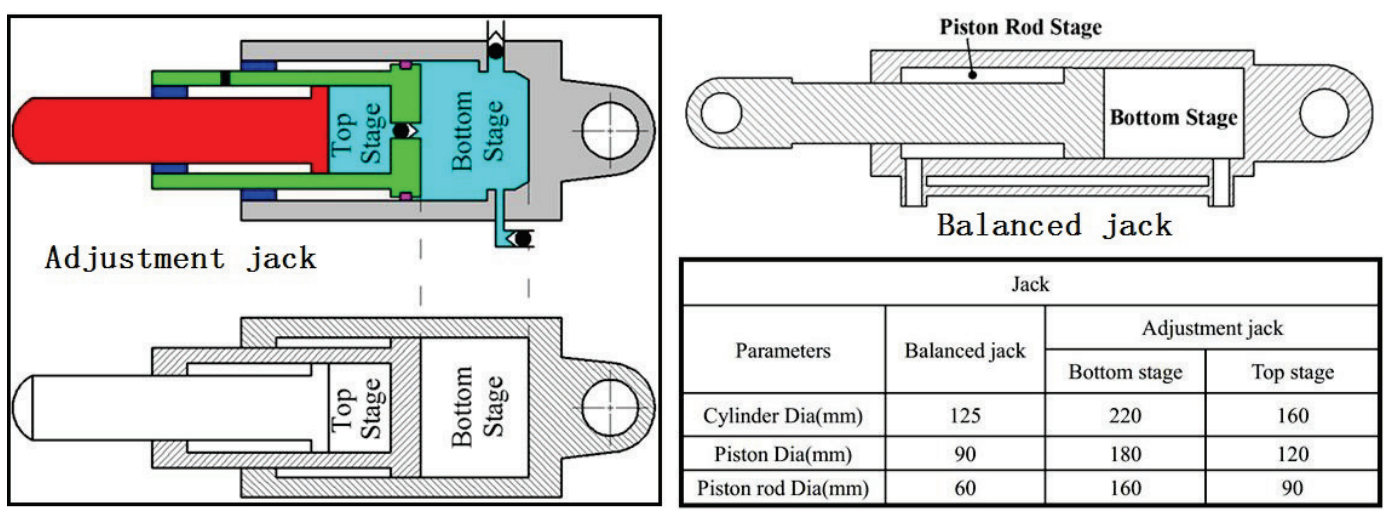

Balanced jack

Figure 6 The stiffness calculation diagram and the radial structural sizes of each hydro-cylinder

\begin{tabular}{|c|c|c|c|c|}
\multicolumn{5}{|c|}{ Table 1 The length of the liquid column (mm) } \\
\hline \multirow{2}{*}{$\begin{array}{c}\text { Working } \\
\text { height }\end{array}$} & \multicolumn{3}{|c|}{ Hydro-cylinder } \\
\cline { 2 - 5 } & Adjustment jack & Top stage & Bottom stage & Piston rod stage \\
\cline { 2 - 5 } & Bottom stage & 0 & 63.38 & 236.62 \\
\hline $900 \mathrm{~mm}$ & 27.52 & 0 & 191.06 & 108.94 \\
\hline $1200 \mathrm{~mm}$ & 212.61 & 210 & 273.08 & 26.92 \\
\hline $1500 \mathrm{~mm}$ & 310 & \multicolumn{2}{c}{} \\
\hline
\end{tabular}

Table 2 The equivalent stiffness of liquid in hydro-cylinder when the support is at different working heights

\begin{tabular}{|c|c|c|c|}
\hline \multirow{3}{*}{ Working height } & \multicolumn{3}{|c|}{ Hydro-cylinder } \\
\hline & \multicolumn{2}{|c|}{ Adjustment jack } & Balanced jack \\
\hline & Type of equivalent stiffness & Equivalent stiffness & Equivalent stiffness \\
\hline $900 \mathrm{~mm}$ & Equivalent stiffness of bottom stage & $1.8031 \times 10^{9}$ & $2.91 \times 10^{7}$ \\
\hline $1200 \mathrm{~mm}$ & Equivalent stiffness of bottom stage & $2.334 \times 10^{8}$ & $6.33 \times 10^{7}$ \\
\hline $1500 \mathrm{~mm}$ & Tandem stiffness & $6.34 \times 10^{7}$ & $2.560 \times 10^{8}$ \\
\hline
\end{tabular}

\subsection{Parameters Setting of the Rigid-Flexible Coupling Simulation Model}

Import the top beam, shield beam, front linkage and rear linkage after flexible processing into the ADAMS simulation model to replace the corresponding rigid structural body, then the ADAMS simulation model of the support is a rigid-flexible coupling model. The material properties of the components are defined, density $\rho=7860$ $\mathrm{kg} / \mathrm{m}^{3}$, Young's modulus $E=2.1 \times 10^{11} \mathrm{~Pa}$, Poisson's ratio $\mu$ $=0.3$. Define the corresponding constraints in the master node of each flexible structural body hinge point's rigidly connected area: Define the base fixed on the ground, and the connection mode at the hinge joint between the top beam and the shield beam, the shield beam and front linkage and rear linkage, front linkage and rear linkage and the base are defined as the rotary pair. Set the frictional coefficient between the two connected components of the rotating deputy to 0.1 , define the movement between the slider and inclined slideway as linear motion pair and set the frictional coefficient of the motion pair to $0.1-0.5$ and the interval to 0.1 in the simulations of different slideway materials. The adjustment jack and balanced jack are substituted by the spring damping with the calculated stiffness.

\subsection{Apply Load}

To compare with the theoretical model, roof pressure is vertically loaded at the point on the central axis of the top beam where the distance from the hinge point of the shield beam is $1 / 3$ top beam length. With the use of the Step function $F_{1}=$ STEP (time, $\left.0,0,0.5,2100\right)+$ STEP (time, $0.5,2100,1,2100)$, the $F_{1}$ will increase gradually from 0 to
$2100 \mathrm{KN}$ and the force will be applied at $2100 \mathrm{KN}$ for a period of time, as shown in Fig. 7 and Fig. 8. After the rigid-flexible coupling model of the support in response to stress is stable, extract the simulation results at steady state.

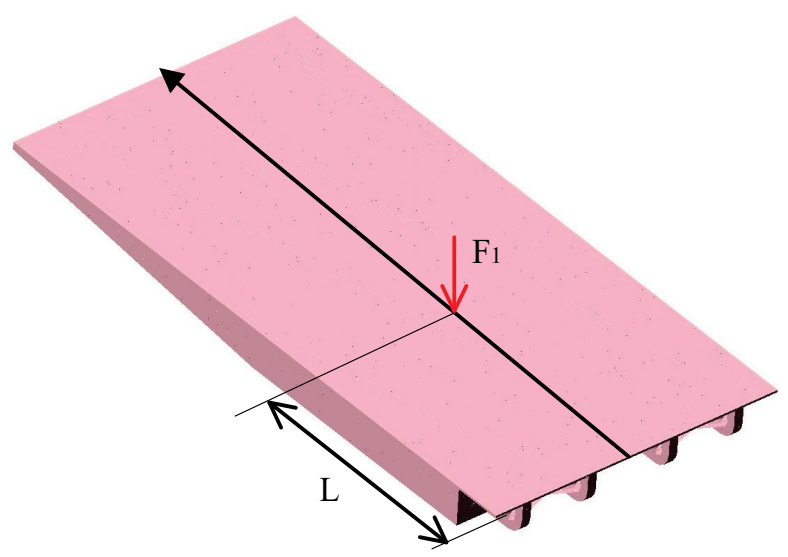

Figure 7 Diagram of the roof pressure loading location

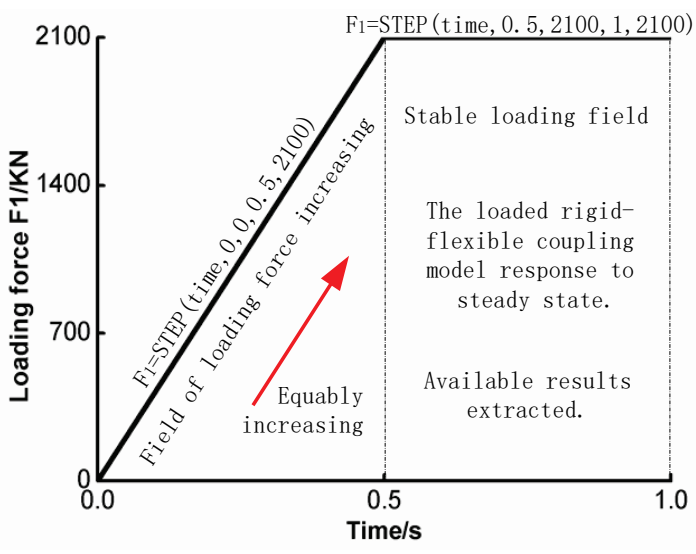

Figure 8 Diagram of the roof pressure loading process 


\section{ANALYSIS RESULTS AND DISCUSSION}

Take independent designed slider-type powered support as the research object, the largest structural height of the support is $1.5 \mathrm{~m}$, the minimum structural height is $0.8 \mathrm{~m}$, the slideway obliquity is $30^{\circ}$, maximum working resistance is $2100 \mathrm{KN}$ and the normal mining height from 1100 to $1200 \mathrm{~mm}$. Through the establishment of the theoretical model and multi-body dynamics simulation analysis, the relationship between the supporting efficiency $\eta$ and frictional coefficient $f$ is studied. The angle parameters of the powered support when the working height is $900 \mathrm{~mm}, 1200 \mathrm{~mm}$ and $1500 \mathrm{~mm}$ are obtained respectively, as shown in Table 3.

Table 3 The angle parameters of the support

Table 3 The angle parameters of the support
\begin{tabular}{|c|c|c|c|}
\hline$H / \mathrm{mm}$ & 900 & 1200 & 1500 \\
\hline$\theta_{1}{ }^{\circ}$ & 39.14 & 54.93 & 82.24 \\
\hline$\theta_{3}{ }^{\circ}$ & 15.47 & 34.64 & 59.35 \\
\hline$\theta_{4} /^{\circ}$ & 16.04 & 32.14 & 54.27 \\
\hline$\theta_{5}{ }^{\circ}$ & 10.41 & 18.93 & 30.90 \\
\hline$\theta_{6}{ }^{\circ}$ & 32.07 & 51.95 & 75.06 \\
\hline$\theta_{7}{ }^{\circ}$ & 30 & 30 & 30 \\
\hline$\theta_{8} /^{\circ}$ & 14.93 & 19.20 & 22.60 \\
\hline
\end{tabular}

\subsection{Analysis of Theoretical Results}

According to the conditions of the construction of mathematical model, we can learn that the powered support is defined at the static equilibrium state, the position and posture of the support have not changed before and after the loading force and the top beam always remains horizontal. Based on the supporting efficiency equation (5) of the slider-type powered support and the angle parameters of the slider-type powered support in Table 1, we get the responsive force $F_{\mathrm{TG}}\left(F_{\mathrm{TG}}=F_{78} / 2\right)$ of the adjustment jack and the supporting efficiency $\eta$ of the support with different frictional coefficients and different working heights under the same roof pressure condition, as shown in Tab. 4 and Tab. 5.

Table 4 Responsive force $\left(10^{6} \mathrm{~N}\right)$ of the adjustment jack with different $f$

\begin{tabular}{|c|c|c|c|c|c|}
\hline$H$ & 0.1 & 0.2 & 0.3 & 0.4 & 0.5 \\
\hline 900 & 1.8835 & 1.8288 & 1.7767 & 1.7272 & 1.6800 \\
\hline 1200 & 1.0715 & 1.0076 & 0.94605 & 0.88668 & 0.82938 \\
\hline 1500 & 0.6 .0365 & 0.52963 & 0.45747 & 0.38708 & 0.31841 \\
\hline
\end{tabular}

Table 5 Supporting efficiency $\eta$ with different frictional coefficients

\begin{tabular}{|c|c|c|c|c|c|}
\hline$H$ & 0.1 & 0.2 & 0.3 & 0.4 & 0.5 \\
\hline 900 & 55.75 & 57.42 & 59.10 & 60.79 & 62.50 \\
\hline 1200 & 98.00 & 104.21 & 110.99 & 118.42 & 126.60 \\
\hline 1500 & 173.94 & 198.25 & 229.53 & 271.26 & 329.76 \\
\hline
\end{tabular}

According to Tab. 4 and Tab. 5, the changing curves of the responsive force of the adjustment jack and the supporting efficiency of the slider-type powered support with different frictional coefficients are established respectively, as shown in Fig. 9 and Fig. 10.

It can be seen from Fig. 9, when powered support's working at the same heights, the pressure of adjustment jack decreases gradually with the increasing of the frictional coefficient. As the powered supports with the same frictional coefficient sets but working at different heights, the pressure of adjustment jack also decreases gradually with the increasing of the frictional coefficient, the higher the working height is, the lower the pressure reduction value is, and the larger the value of the frictional coefficient is, the larger the pressure reduction value is.

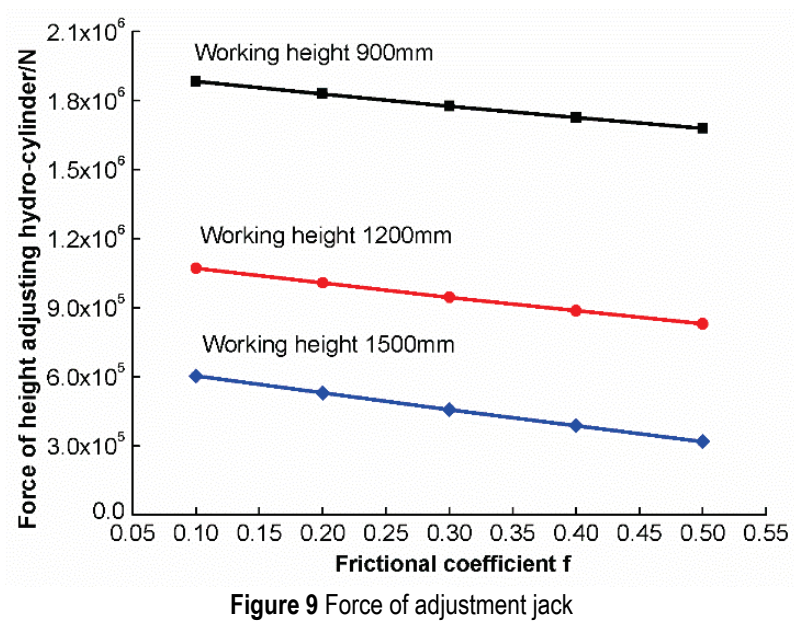

From Fig. 10, when powered support is working at the same height, the supporting efficiency of the slider-type powered support decreases gradually with the increasing of the frictional coefficient. When the working height of the support is higher, with the increase in the frictional coefficient, the greater is the growth rate of supporting efficiency. For the powered supports with the same frictional coefficient, with the increase of the working height of support, the supporting efficiency increases accordingly, and the growth rate also increases.

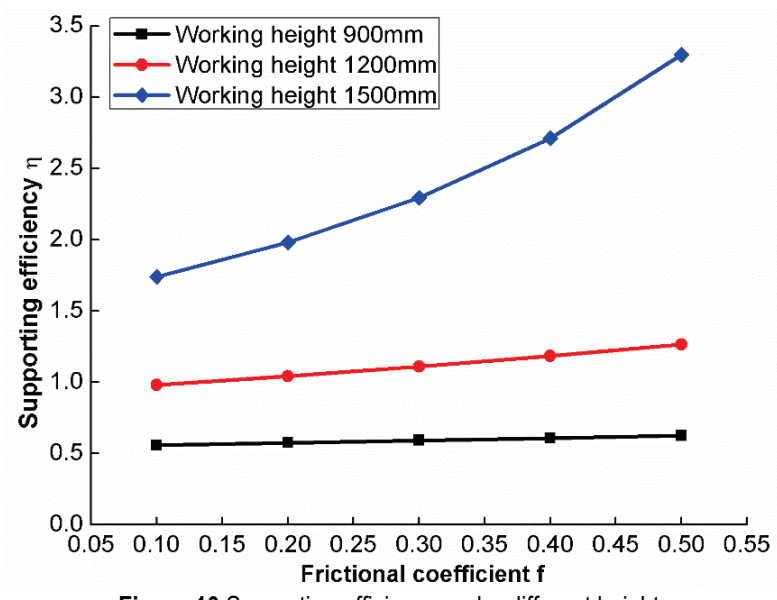

Figure 10 Supporting efficiency under different heights

Therefore, from the theoretical solution obtained by the theoretical model, the higher the working height of the support and the larger the frictional coefficient, the smaller the oil pressure demand for the adjustment jack, the larger supporting efficiency of the support, and the pressure demand on the pump also goes down. Under this condition, the powered support has better energy saving effect and higher working security.

\subsection{Simulation Analysis}

In the simulation process, the roof pressure is loaded according to the roof pressure equivalent method of the theoretical model, but there is no constraint on the top beam of the simulation model. In this state, the top beam, 
front and rear linkage, shield beam and vertical bar will reach another steady state after the action of the concentrated force $F_{1}$ applied and the original equilibrium state is destroyed. In the process, the top beam will be deflected through angles. After the simulation on the multibody rigid-flexible coupling dynamics simulation model of the powered support under different working heights and different frictional coefficients, the responding results of each component are obtained.

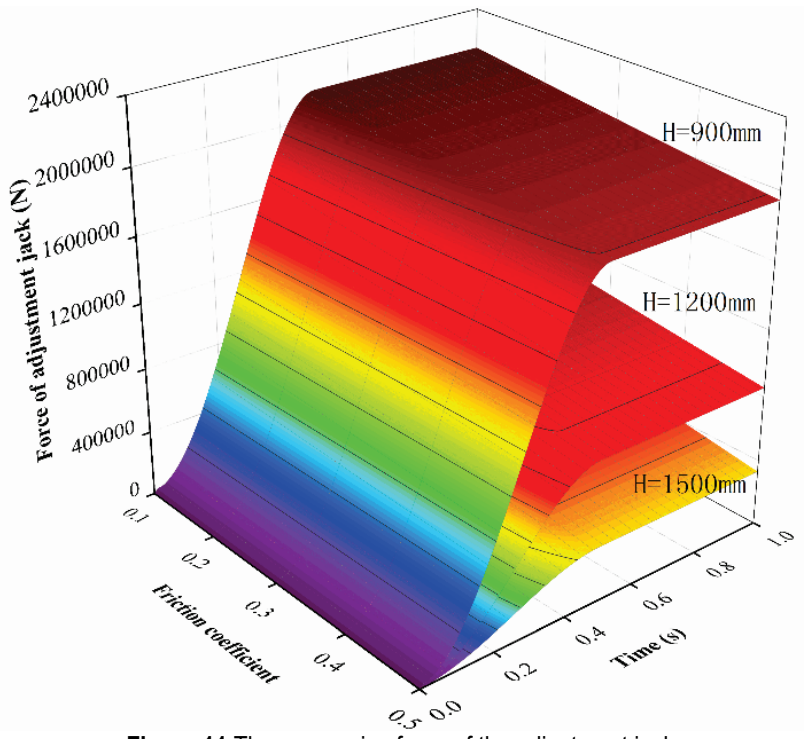

Figure 11 The responsive force of the adjustment jack

Fig. 11 shows the pressure response curves of the adjustment jack when the working height is $900 \mathrm{~mm}, 1200$ $\mathrm{mm}$ and $1500 \mathrm{~mm}$ respectively. In the simulation, the load is increased in the first $0.5 \mathrm{~s}$, and then maintained the stable state after $0.5 \mathrm{~s}$. The three stages of the response of adjustment jack in the simulation model can be obtained from the simulation results: (1) First response stage: When the load is applied, the load is equivalent to the impact load in a relatively short period of time. With the increase of the load, the pressure of the adjustment jack appears three polygonal lined ladder increasing type shock response, and the response is completed in a very short time $(t<0.03 \mathrm{~s})$. (2) Second response stage: After the first response stage, as the load continues to increase, the pressure of the adjustment jack shows a tendency of increasing in twisted pair lines and the response ends when the load reaches the preset value ( $t=0.5 \mathrm{~s})$. (3) Third response stage: When the load reaches the preset value, it will continue to apply for a period of time to make the whole support transit to the stable state and the pressure of the adjustment jack will no longer change.

The process of first response stage is shown in Fig. 12, after the responsive force of the adjustment jack increased to a certain value in a growth rate, the growth rate decreases instantly to a smaller value and the responsive force of the adjustment jack maintains steady increase. At last, with the continuous increase of the impact load, the responsive force of the adjustment jack maintains steady increase. At this stage, because of the existence of the shock response, the responsive force changing trend of the hydraulic oil in the adjustment jack is not stable. At the same time, due to the compressibility of the hydraulic oil in the adjustment jack, the hydraulic oil will tremble in the adjustment jack which causes irregular impact on the cylinder wall. Under this working condition, it is easy to cause bad influence on the service life and safety of adjustment jack and the working stability of the support. Based on this, the slidertype powered support should avoid bearing the impact load in the using process.

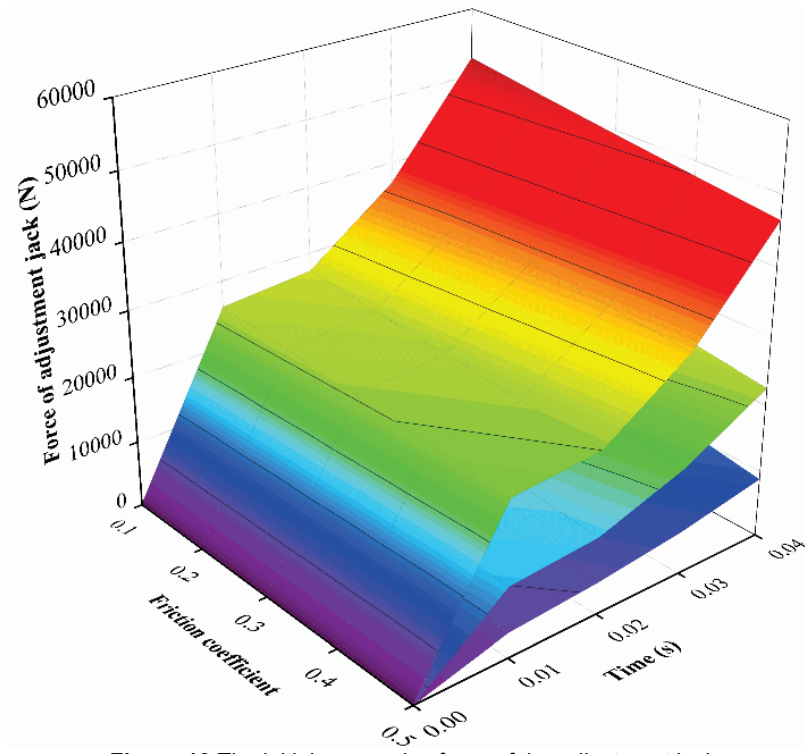

Figure 12 The initial responsive force of the adjustment jack

According to the above, we also know that in the whole response stage, the responsive force of the adjustment jack decreases gradually with the increase of frictional coefficient. However, when the frictional coefficient keeps constant, the responsive force of the adjustment jack and its reduction rate decrease with the increase of the working height of the support.

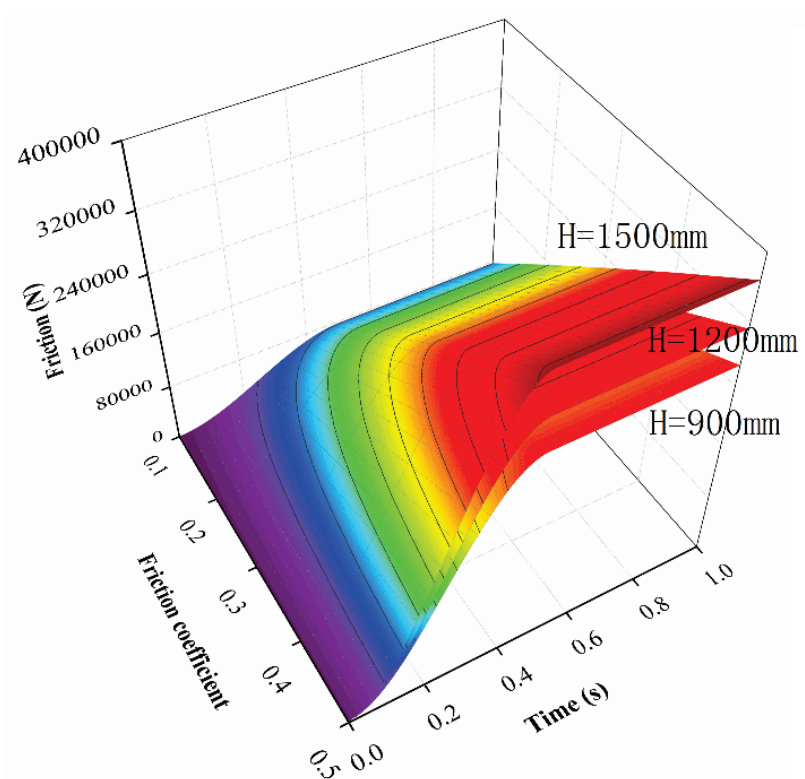

Figure 13 Friction between the slider and slideway

Fig. 13 shows the friction curves of the slider-type powered support between the slider and slideway when the working height is $900 \mathrm{~mm}, 1200 \mathrm{~mm}$ and $1500 \mathrm{~mm}$ respectively. The friction is far less than responsive force of the adjustment jack. The change of friction between the slider and slideway in the simulation also presents three 
stages: (1) Stage of three polylined ladder increasing type shock response, (2) Lemniscated trend increasing stage, (3) Stabilization stage. The three stages correspond to the first, second, third pressure response stage of adjustment jack. For slider-type powered support working at any height, when the support is bearing the roof pressure $F_{1}$, with the increase of frictional coefficient, the friction between the slider and slideway increases accordingly, but the increasing speed decreases gradually in the whole responding stage. Under the same frictional coefficient, the friction between the slider and slideway increases with the increase of the working height.

In combination with Figs. 11-13, for the hydraulic support working at three different working heights, when the first stage response under the roof pressure appears, with the increase of the frictional coefficient, the responding load of the adjustment jack will decrease gradually at any point in the first stage response and the friction between the slider and the slideway will also increase gradually at the same time. The cause of this phenomenon is that, for any working height of the slidertype powered support, when the pressure of the roof increases gradually from 0 , the sliding distance of slider along the slideway is very short and the position and posture is considered not changed in a very short time. At the same time, as the positive pressure of the slider decomposed on the slideway taken as constant value since the force transmitted from the roof to the slider through the top beam and vertical bar is constant, with the change of the frictional coefficient, the greater the frictional coefficient between the slider and the slide-way, the greater the friction generated by the positive pressure. In this state, the energy absorbing ability produced by the slider friction increases gradually, the sliding distance and amplitude decrease when bearing the same shock load. Although the buffer performance of the support is reduced, the shock resistance and stability of the support are enhanced.

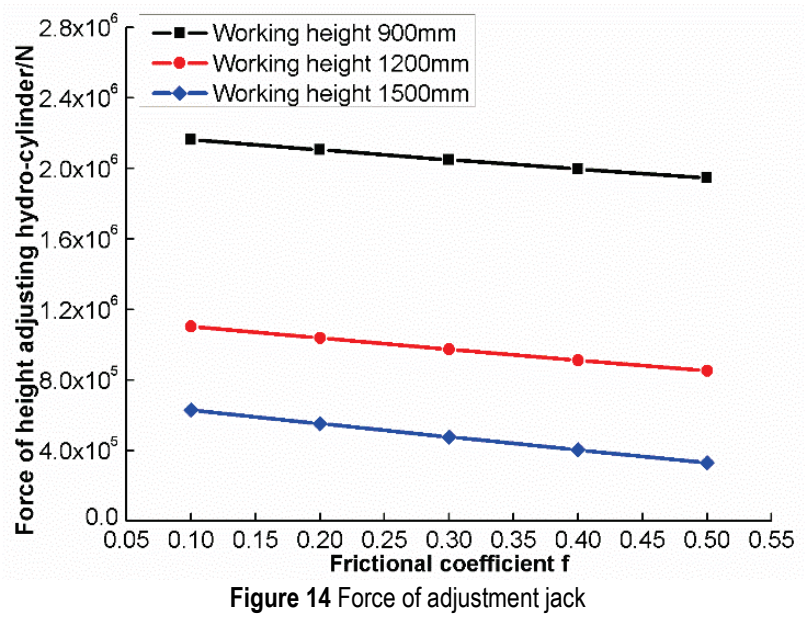

In the working process, the adjustment jack of the support is in the passive supporting state. Under the roof pressure, the friction between the slider and the slideway acts as a force to block the slider from sliding down the slideway and supports the roof with the adjustment jack. Therefore, at the passive supporting stage and with the constant roof pressure, the larger the frictional coefficient between the slider and the slideway and the working height is, the greater the friction generated between the slider and the slideway is, the greater the energy contribution to the roof support process is and the demanding for the supporting force provided by the adjustment jack will reduce which saves the total energy in the working process.

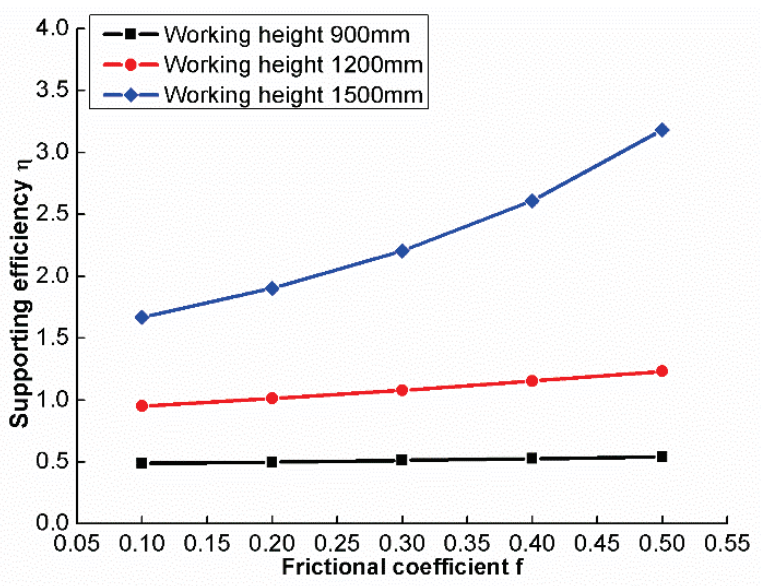

Figure 15 Changing curves of supporting efficiency

From the extraction of the simulation data in the stabilization stage, we can obtain the pressure changing curves of the adjustment jack and the supporting efficiency changing curves with the change of the frictional coefficient which is shown in Fig.14 and Fig.15. It can be seen from Fig. 13 that the pressure of the adjustment jack decreases gradually with the increase of the frictional coefficient when the powered support is working at the same height. For the support working at different heights but with the same frictional coefficient, the pressure of the adjustment jack decreases gradually with the increase of the working height, the higher the working height, the smaller the pressure drop, and the larger the frictional coefficient, the larger the pressure drop. From Fig.14, for the powered support working at the same height, supporting efficiency increases gradually with the increase of the frictional coefficient. When the working height of the support is increasing, the growth rate of supporting efficiency becomes larger with the increase of frictional coefficient. For the hydraulic powered support with the same frictional coefficient, with the increase of the working height, the supporting efficiency increases gradually and the growth rate also increases. According to Fig.9 and Fig.10, although the constraint definition exist differences between the process of the theoretical model establishment and the simulation process, the supporting efficiency and the pressure of the adjustment jack show the same changing trend with the change of friction coefficient in the theory results and simulation results under the same roof contact and roof pressure.

\subsection{Comparative Analysis of Theory and Simulation}

Tab. 6 and Tab. 7 list the theoretical values T-Values and simulation results $\mathrm{S}$-Results of the responsive force $F_{\mathrm{TG}}$ of the adjustment jack and supporting efficiency $\eta$ of the support with different frictional coefficients between the slider and slideway, where the support working at the stable state and the working height is $900 \mathrm{~mm}, 1200 \mathrm{~mm}$ and $1500 \mathrm{~mm}$ respectively. At the same time, the difference values D-Values and difference ratios D-Ratios 
of $F_{\mathrm{TG}}$ and $\eta$ in the theoretical establishment and simulation process are obtained. According to Tab. 6 and Tab. 7, the changing curves of the theory and simulation values of the pressure of the adjustment jack, supporting efficiency of the support, the difference value and difference ratio of the pressure of the adjustment jack and the difference values and difference ratios of the supporting efficiency are set up, as shown in Fig. 16 to Fig. 19.

Table 6 Pressure of the adjustment jack $\left(10^{5} \mathrm{~N}\right)$

\begin{tabular}{|c|c|c|c|c|c|c|c|c|c|c|c|c|c|c|c|}
\hline \multirow[b]{2}{*}{$f$} & \multicolumn{5}{|c|}{ Working height $900 \mathrm{~mm}$} & \multicolumn{5}{|c|}{ Working height $1200 \mathrm{~mm}$} & \multicolumn{5}{|c|}{ Working height $1500 \mathrm{~mm}$} \\
\hline & 0.1 & 0.2 & 0.3 & 0.4 & 0.5 & 0.1 & 0.2 & 0.3 & 0.4 & 0.5 & 0.1 & 0.2 & 0.3 & 0.4 & 0.5 \\
\hline T-Values & 18.84 & 18.29 & 17.77 & 17.27 & 16.80 & 10.72 & 10.08 & 9.461 & 8.867 & 8.294 & 6.037 & 5.296 & 4.575 & 3.871 & 3.184 \\
\hline S-Results & 21.63 & 21.05 & 20.49 & 19.96 & 19.46 & 11.04 & 10.38 & 9.738 & 9.119 & 8.521 & 6.292 & 5.518 & 4.762 & 4.023 & 3.300 \\
\hline D-Values & 2.795 & 2.761 & 2.727 & 2.693 & 2.658 & 0.325 & 0.302 & 0.277 & 0.252 & 0.227 & 0.255 & 0.222 & 0.187 & 0.152 & 0.116 \\
\hline D-Ratios & 14.84 & 15.10 & 15.35 & 15.59 & 15.82 & 3.03 & 3.00 & 2.93 & 2.84 & 2.74 & 4.22 & 4.19 & 4.09 & 3.93 & 3.64 \\
\hline
\end{tabular}

Table 7 Supporting efficiency $\eta(\%)$

\begin{tabular}{|c|c|c|c|c|c|c|c|c|c|c|c|c|c|c|c|}
\hline \multirow{2}{*}{$f$} & \multicolumn{5}{|c|}{ Working height $900 \mathrm{~mm}$} & \multicolumn{5}{|c|}{ Working height $1200 \mathrm{~mm}$} & \multicolumn{5}{|c|}{ Working height $1500 \mathrm{~mm}$} \\
\hline & 0.1 & 0.2 & 0.3 & 0.4 & 0.5 & 0.1 & 0.2 & 0.3 & 0.4 & 0.5 & 0.1 & 0.2 & 0.3 & 0.4 & 0.5 \\
\hline T-Values & 55.75 & 57.42 & 59.10 & 60.79 & 62.50 & 98.00 & 104.2 & 111.0 & 118.4 & 126.6 & 173.9 & 198.3 & 229.5 & 271.3 & 329.8 \\
\hline S-Results & 48.57 & 49.88 & 51.23 & 52.59 & 53.96 & 95.11 & 101.2 & 107.8 & 115.2 & 123.2 & 166.9 & 190.3 & 220.5 & 261.0 & 318.2 \\
\hline D-Values & 7.18 & 7.54 & 7.84 & 8.20 & 8.54 & 2.89 & 3.03 & 3.16 & 3.27 & 3.38 & 7.06 & 7.98 & 9.05 & 10.28 & 11.61 \\
\hline D-Ratios & 12.88 & 13.13 & 13.27 & 13.49 & 13.66 & 2.95 & 2.91 & 2.85 & 2.76 & 2.67 & 4.06 & 4.03 & 3.94 & 3.79 & 3.52 \\
\hline
\end{tabular}

T-Values: Theoretical values; S-Results: Simulation results; D-Values: Difference values; D-ratios: Difference ratios

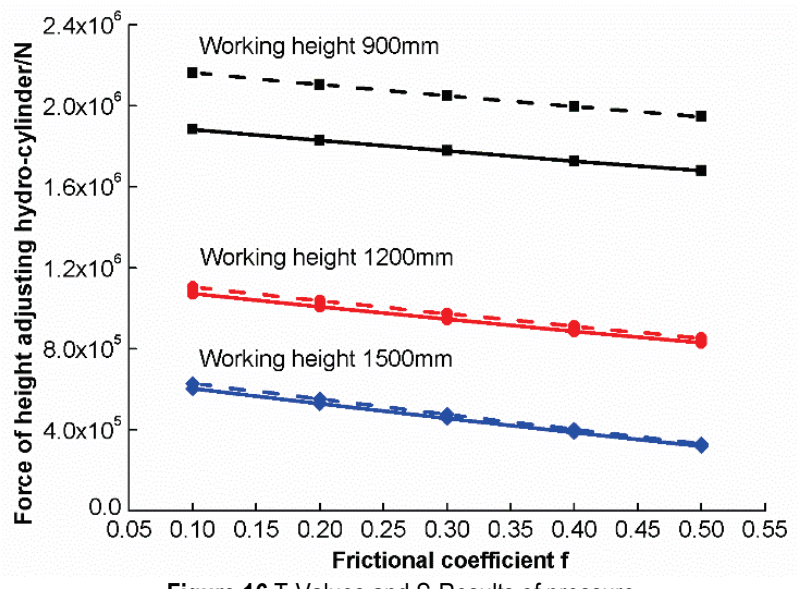

Figure 16 T-Values and S-Results of pressure

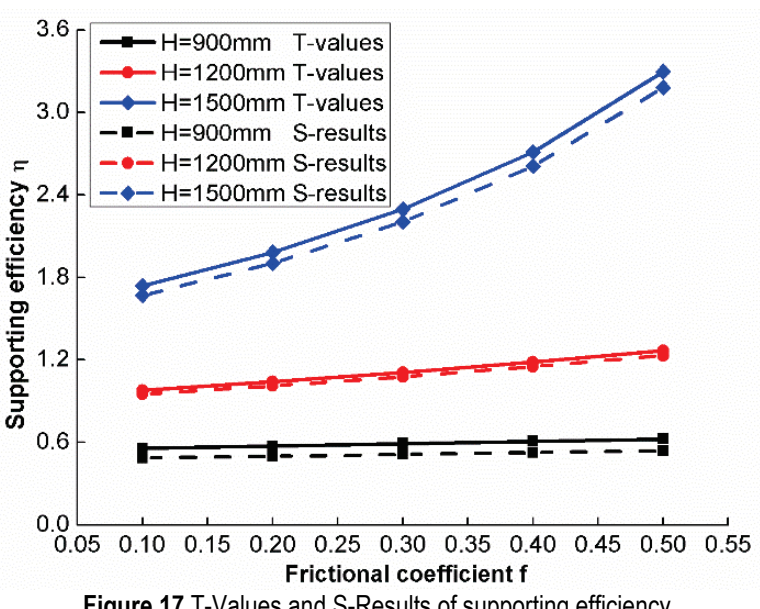

As shown in Fig. 16 and Fig. 17, although the changing trends of the pressure of the adjustment jack and supporting efficiency with the change of the friction coefficient from the theoretical and simulation results are similar, there are still some differences. When powered support is working at $900 \mathrm{~mm}, 1200 \mathrm{~mm}$ and $1500 \mathrm{~mm}$, the theoretical values of the pressure of the adjustment jack are smaller than those of the simulation values, and the theoretical values of the supporting efficiency are greater than those of the simulation values. In addition, it can be obtained from Figs. 16-19 that with the increasing of the frictional coefficient, the difference between the theoretical values and the simulation values of the pressure of the adjustment jack decreases gradually, and the difference between the theoretical values and the simulation values of the supporting efficiency gradually increases.

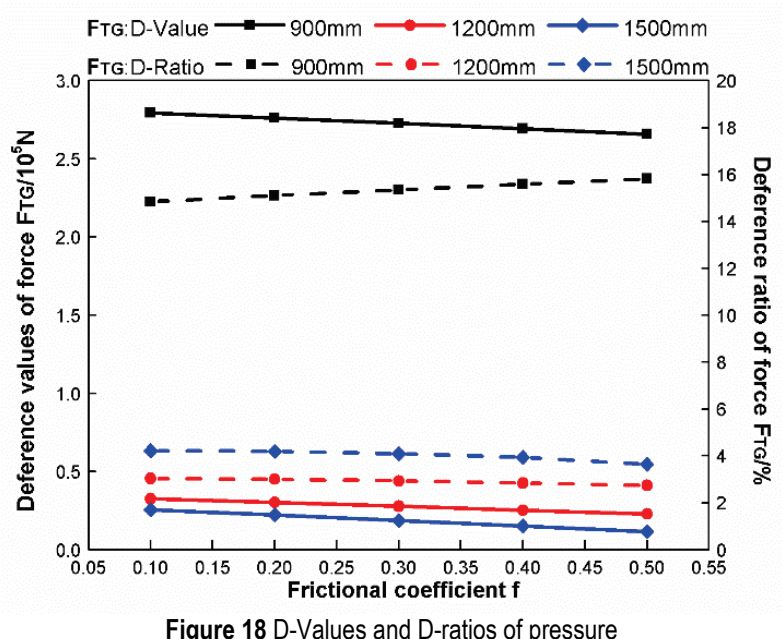

It can be found from Fig. 18 and Fig. 19 that when the powered support is working at $900 \mathrm{~mm}$, the difference ratios between the theoretical values and the simulation values of the pressure of the adjustment jack and supporting efficiency are larger, the difference ratios between the theoretical values and the simulation values of the pressure of the adjustment jack are between 14-16\%, the difference ratio between the theoretical value and the simulation value of the supporting efficiency is between $12-14 \%$, and the difference ratios between the theoretical values and the simulation values of the pressure of the adjustment jack and supporting efficiency are increasing with the increase of frictional coefficient. When powered support is working at $1200 \mathrm{~mm}$ and $1500 \mathrm{~mm}$, the difference ratios between the theoretical values and the simulation values of the pressure of the adjustment jack and supporting efficiency are smaller and the difference ratios can be controlled within 5\%. Meanwhile, the difference ratios between the theoretical values and the simulation values of the pressure of the adjustment jack 
and supporting efficiency are decreasing with the increase of frictional coefficient.

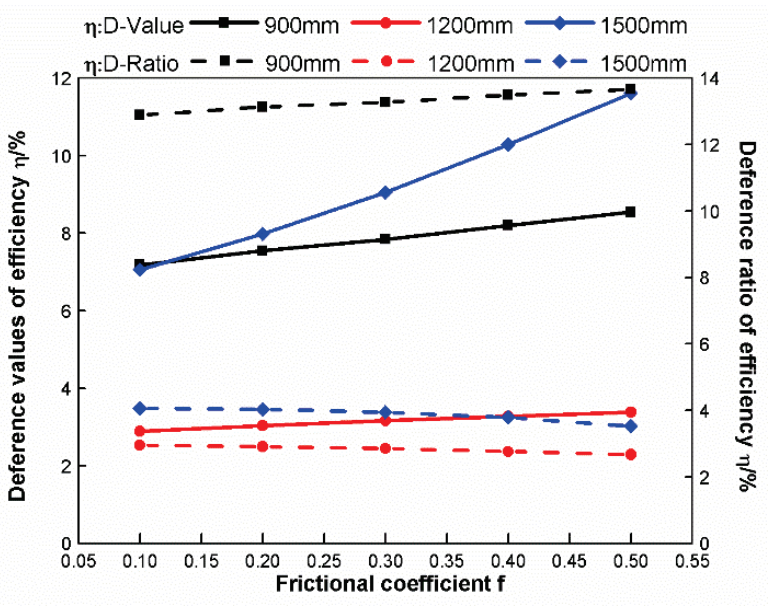

Figure $19 \mathrm{D}$-Values and D-ratios of supporting efficiency

\subsection{Analysis and Discussion}

Although the theoretical and simulation results show that the supporting efficiency and the pressure of the adjustment jack with the change of the friction coefficient have the same changing trend, there are still some differences and the reason is the following: (1) In the constructing process of the theoretical model, it is considered that the support is in static equilibrium and the top beam keeps horizontal, but in the process of simulation, the top beam had not been imposed to constraints. Therefore, there is a certain difference in the position and posture of the powered support in the final steady state between the theoretical model and simulation. (2) In the constructing process of the theoretical model, the structure of the support is equivalent to the rigid body, but in the simulation, the main components of the support such as top beam, shield beam, front linkage and rear linkage went through flexible processing. (3) In the constructing process of the theoretical model, the compressibility of the hydraulic oil in the hydro-cylinder is neglected, but in the simulation, the hydro-cylinder is considered equivalent to a spring with certain stiffness. (4) In the constructing process of the theoretical model, friction at the connection position of different components is neglected except the friction between the slider and slideway, but in the simulation, not only the friction between the slider and the slideway should be considered but also the 'rotating pairs' of the different components of the support need to be defined as the friction. (5) In the constructing process of the simulation model of the slider-type powered support, allowance is retained in the connection position of different components (such as the clearance between pinhole and hinge pin), which has not been considered in the construction of the theoretical model.

When the support is working at $1200 \mathrm{~mm}$ and 1500 $\mathrm{mm}$, the difference values and difference ratios of the pressure of the adjustment jack and supporting efficiency between theory and simulation have the same changing trend, at the same time, the difference ratios between theory and simulation are smaller and the results are more accurate. When the support is working at $900 \mathrm{~mm}$, although the changing tendency of the difference values of the pressure of the adjustment jack and supporting efficiency between theory and simulation is the same with the working height $1200 \mathrm{~mm}$ and $1500 \mathrm{~mm}$, but the changing trends of the difference ratios are in the opposite direction, the difference ratios between theory and simulation are larger and the accuracy of the results is lower comparatively. The reason is that the length of effective fluid column in the hydro-cylinder is shorter when the support is working at $900 \mathrm{~mm}$, which caused the equivalent stiffness to be too large and the loading response of the support is not obvious. But powered supports rarely work near the lowest working position and the results got from the working height $1200 \mathrm{~mm}$ and $1500 \mathrm{~mm}$ are more persuasive. Overall, the changing trends of the loading components got from the theory and simulation are the same and the difference ratios are in allowable range, which verifies the correctness of the construction of theoretical model and the feasibility to instead the hydrocylinder by spring with a certain stiffness and carry out the rigid-flexible coupling simulation analysis to the support are also proved. The changing trends of the pressure of the adjustment jack and supporting efficiency with the change of the frictional coefficient between the slider and slideway according to the results got from the theoretical model and simulation are correct and reliable.

According to the results of theory and simulation, when the powered support is working at the same height, the pressure of the hydro-cylinder decreases gradually with the increase of frictional coefficient but the supporting efficiency of the support is gradually increased. For the powered support working at the different heights but with the same frictional coefficient, with the increase of the working height: (1) The pressure of adjustment jack is gradually reduced, the higher the working height, the smaller the pressure drop. Meanwhile, the greater the frictional coefficient, the smaller the pressure drop. (2) The supporting efficiency and its growth rate increase gradually. It can be seen that the higher the working height and the greater the frictional coefficient, the smaller the pressure demand for the adjustment jack under the same roof contact condition and roof pressure, and the higher the supporting efficiency is, the lower the pressure demand of the hydraulic pump station is. Under the same pressure of the adjustment jack, the higher the working height and the greater the frictional coefficient, the greater the roof pressure which slider-type powered support can bear. Meanwhile, the safety and reliability of the support become higher. Therefore, slider-type powered support has the characteristics of energy saving, high reliability and safety. The greater the working height and the frictional coefficient of the slider and slideway, the more obvious the advantages.

From the point of improving the supporting efficiency, reducing the mining cost, improving the stability and antiimpact property, it is a benefit for the designing of slidertype powered support if the selected frictional coefficient between the slider surface material and the steel material (Materials for slider making) is larger. However, different materials have different hardness and wear resistance which will affect the service life and reliability of the support. The difference of production cost of material and processing technology will also affect the market competitiveness of the support. Therefore, it is necessary 
to select the slider surface material with large frictional coefficient while comprehensively considering the working height of the support, material hardness and wear resistance, production and manufacturing cost, etc.

\section{CONCLUSIONS}

Put forward a new design concept for the slider-type powered support, establish the equivalent mechanical model when bearing the stable roof pressure, deduce the numerical calculation equation of the supporting efficiency based on the frictional coefficient between the slider and slideway. The rigid-flexible coupling simulation model of the support is established by using Hypermesh and Adams jointly and the spring is used to replace the adjustment jack and balanced jack. By determining the reasonable spring stiffness, the simulation of compression positive pressureboosting characteristics of the hydro-cylinder oil is achieved, and the dynamic simulation under stable roof pressure is carried out based on the above.

Through the contrast analysis of the theoretical values and simulation results, the results of the simulation fit perfectly to the theoretically calculated results, and the error between the theoretical values and simulation results is very small, which proves the scientificity of the constructed theoretical model and the correctness of the simulation results, as well as the feasibility of the simulation method. The following conclusions are drawn:

1) With the increase of frictional coefficient between the slider and slideway, the supporting efficiency increases gradually, the working safety and reliability of the support are enhanced and the pressure demand for the hydraulic pump station is reduced when the support is supporting the same roof.

2) The increasing of the frictional coefficient between the slider and slideway reduces the cushioning performance of the support, but improves the anti-impact performance and enhances the stability of the support.

3) Slider-type powered support is more suitable for working at high position and it can save the energy of hydraulic systems, but the impact load should be avoided in using the process.

4) It is necessary to select the material of the slider surface with large frictional coefficient in the designing process of the slider-type powered supportwhile the working height of the support, material hardness and wear resistance, production and manufacturing cost and other factors are considered comprehensively.

The research will provide theoretical reference for the design and application of the slider-type powered support, and provide a rigid-flexible coupling simulation method for the analysis of the slider-type powered support.

\section{Acknowledgements}

This work was supported by National Natural Science Foundation of China (Grant No. 51674155), Innovative Team Development Project of Ministry of Education (Grant No. IRT 16R45), Special funds for Climbing Project of Taishan Scholars, Key research and development project of Shandong province (Grant No. 2018GGX103027)

\section{REFERENCES}

[1] Wang, J. H., Yu, B., Kang, H. P. et al. (2015). Key technologies and equipment for a fully mechanized top-coal caving operation with a large mining height at ultra-thick coal seams. International Journal of Coal Science \& Technology, 2(2), 97-16. https://doi.org/10.1007/s40789-015-0071-4

[2] Vakili, A. \& Hebblewhite, B. K. (2010). A new cavability assessment criterion for Longwall Top Coal Caving. International Journal of Rock Mechanics \& Mining Sciences, 47, 1317-1329. https://doi.org/10.1016/j.jirmms.2010.08.010

[3] Khanal, M., Adhikary, D., \& Balusu R. (2011).Evaluation of mine scale longwall top coal caving parameters using continuum analysis. Mining Science and Technology (China), 21, 787-796. https://doi.org/10.1016/j.mstc.2011.06.027

[4] Yasitli, N. E. \& Unver, B. (2005). 3D numerical modeling of longwall mining with top-coal caving. International Journal of Rock Mechanics \& Mining Sciences, 42, 219-235. https://doi.org/10.1016/j.jirmms.2004.08.007

[5] Ma, Y. Y., Xie, L. W., \&Qin, X. F. (2012). Strength and Reliability Analysis of Hydraulic Support. Advanced Materials Research, 544, 18-23. https://doi.org/10.4028/www.scientific.net/AMR.544.18

[6] Goktay Ediz, I., Dixon-Hardy, D. W., Akcakoca, H. et al. (2013). Application of retreating and caving longwall (top coal caving) method for coal production at GLE Turkey. Mining Technology (Transactions of the Institutions of Mining and Metallurgy: Section A), 115(2), 41-48. https://doi.org/10.1179/174328606X103586

[7] Wang, G. F. (2013). Finite New development of longwall mining equipment based on automation and intelligent technology for thin seam coal. Journal of Coal Science \& Engineering, 19(1), 97-103. https://doi.org/10.1007/s12404-013-0116-5

[8] Zhang, Q., Zhang, J. X., Kang, T. et al. (2015). Mining pressure monitoring and analysis in fully mechanized backfilling coal mining face-A case study in Zhai Zhen Coal Mine. Journal of Central South University of Technology, 22, 1965-1972. https://doi.org/10.1007/s11771-015-2716-2

[9] Yu, L., Yan, S. H., Yu, H. Y. et al. (2011). Studying of dynamic bear characteristics and adaptability of support in top coal caving with great mining height. Procedia Engineering, 26, 640-646. https://doi.org/10.1016/j.proeng.2011.11.2217

[10] Zhang, Q., Zhang, J. X., Tai, Y. et al. (2015). Horizontal roof gap of backfill hydraulic support. Journal of Central South University of Technology, 22, 3544-3555. https://doi.org/10.1007/s11771-015-2894-y

[11] Wang, G. F. (1999). Powered Support Technology. China Coal Industry Publishing House, Beijing, China.

[12] Wang, G. F. (2010). Top-Caving Powered Support and Fully-Machanized Caving Technology. China Coal Industry Publishing House, Beijing, China.

[13] Marcin, W. \& Stanisław, P. (2016). Numerical calculations of shield support stress based on laboratory test results. Computers and Geotechnics, 72, 74-88. https://doi.org/10.1016/j.compgeo.2015.11.007

[14] Tu, S. H., Yuan, Y., Li, N. L. et al. (2008). Hydraulic support stability control of fully mechanized top coal caving face with steep coal seams based on instable critical angle. Journal of Coal Science \& Engineering, 14(3), 382-385. https://doi.org/10.1007/s12404-008-0084-3

[15] Barczak, T. \& Gerhart, D. (1998). Performance and safety considerations of hydraulic support system. In Proceedings of the $17^{\text {th }}$ International Conference on Ground Control in Mining, 176-186, Morgantown.

[16] Zhao, T., Liu, C. Y., Yetilmezsoy, K. et al. (2017). Realization and engineering application of hydraulic support 
optimization in residual coal remining. Journal of Intelligent \& Fuzzy Systems, 32, 2207-2219. https://doi.org/10.3233/JIFS-162311

[17] Sun, H. B., Jiang, J. Q., \& Ma, Q. (2011). Research on hydraulic-powered roof supports test problems. Journal of Coal Science and Engineering (China), 17(2), 201-206. https://doi.org/10.1007/s12404-011-0218-x

[18] Singh, G. S. P. \& Singh, U. K. (2009). A numerical modeling approach for assessment of progressive caving of strata and performance of hydraulic powered support in longwall workings. Computers and Geotechnics, 36, 1142-1156. https://doi.org/10.1016/j.compgeo.2009.05.001

[19] Wan, L. R., Liu, P., Meng, Z. S. et al. (2017). Study and analysis on stability of hydraulic powered support for ultra high mining. Coal Science and Technology, 45(1), 148-153. https://doi.org/10.13199/j.cnki.cst.2017.01.025

[20] Fang, C. F., Meng, X. H., Hu, Q. X. et al. (2012). TANDEM and GMAW Twin Wire Welding of Q690 Steel Used in Hydraulic Support. Journal of Iron and Steel Research, International, 19(5), 79-85. https://doi.org/10.1016/S1006-706X(12)60104-6

[21] Xu, G. (2015). Experimental and theoretical study on hydraulic support in working face and its relationship with roof subsidence. Journal of China Coal Society, 40(7), 14851490. https://doi.org/10.13225/j.cnki.jccs.2015.0220

[22] Liao, Y. Y., Lian, Z. S., Long, R. S. et al. (2015). Effects of multiple factors on the stress of the electro-hydraulic directional valve used on the hydraulic roof supports. International Journal of Applied Electromagnetics and Mechanics, 47, 199-209. https://doi.org/10.3233/JAE-140028

[23] Zhang, X., Liu, J., Wang, Z. Y. et al. (2011). The research of the evaluation system for the sealability of hydraulic supports and jacks' seals. Journal of Coal Science and Engineering (China), 17, 104-106. https://doi.org/10.1007/s12404-011-0120-6

[24] Geary, W. (2014).Failure analysis of solenoid valve components from a hydraulic roof support. Case Studies in Engineering Failure Analysis, 1, 209-216. https://doi.org/10.1016/j.csefa.2013.07.004

[25] Bai, Z. F. (2010). Analysis on Impact Strength Big Bore Double Telescopic. Master's Thesis, Xi'an University of Science and Technology, Xi'an, China.

[26] Prebil, I., Krašna, S., \& Ciglarič, I. (2002).Synthesis of fourbar mechanism in a hydraulic support using a global optimization algorithm. Struct Multidisc Optim, 24, 246 -251. https://doi.org/10.1007/s00158-002-0234-y

[27] Nie, W., Cheng, W. M., Zhang, L. et al. (2014). Optimization research of hydraulic support in fully mechanized caving face. Procedia Engineering, 84, 770-778. https://doi.org/10.1016/j.proeng.2014.10.495

[28] Verma, A. \& Deb, D. (2013).Numerical Analysis of an Interaction between Hydraulic-Powered Support and Surrounding Rock Strata. International Journal of Geomechanics, 13, 181-192. https://doi.org/10.1061/(ASCE)GM.1943-5622.0000190

[29] Zhao, X. H., Li, F. Y., Liu, Y. et al. (2015). Fatigue Behavior of a Box-Type Welded Structure of Hydraulic Support Used in Coal Mine. Materials, 8, 6609-6622. https://doi.org/10.3390/ma8105325

[30] González-Nicieza, C., Menéndez-Díaz, A., Álvarez-Vigil A. E. et al. (2008). Analysis of support by hydraulic props in a longwall working. International Journal of Coal Geology, 14, 67-92. https://doi.org/10.1016/j.coal.2007.10.001

[31] Wang, X. W., Yang, Z. J., Feng, J. L. et al. (2013). Stress analysis and stability analysis on doubly-telescopic prop of hydraulic support. Engineering Failure Analysis, 32, 274282. https://doi.org/10.1016/j.engfailanal.2013.04.006

[32] Oblak, M., Harl, B., \& Butinar, B. (2000).Optimal design of hydraulic support. Struct Multidisc Optim, 20, 76-82. https://doi.org/10.1007/s001580050138
[33] Li, W. C., Di, Z. P., \& Feng, L. N. (2014). Application and Improvement of Automatic Technology and Equipment to Fully Mechanized Coal Mining Face in Thin Seam. Coal Science and Technology, 42(9), 40-43. https://doi.org/10.13199 /j.cnki.cst.2014.09.009

[34] Zeng, Q. L., Yang, Y., Meng, Z. S. et al. (2017). Kinematics Characteristics Analysis of New Hexaglide Hydraulic Support for Thin Coal Seam. Coal Technology, 36(2), 214216. https://doi.org/10.13301/j.cnki.ct.2017.02.084

[35] Yang, Y., Zeng, Q. L., Zhou, J. H. et al. (2018). The design and analysis of a new slipper-type hydraulic support. PLOSONE, 13(8), 1-22. https://doi.org/10.1371/journal.pone.0202431

\section{Contact information}

Yang YANG, PhD, candidate student

E-mail: yang.yang@sdust.edu.cn, sdkdyangyang@126.com

Qingliang ZENG, Prof. Dr. (Corresponding author)

E-mail: qlzeng@sdust.edu.cn

Lirong WAN, Prof. Dr.

E-mail: lirong.wan@sdust.edu.cn

Peng LIU, master graduate student

E-mail: pengl0328@163.com

College of Mechanical and Electronic Engineering, Shandong University of Science and Technology, 266590 Qingdao, China 